\title{
NSF reorganizes for industrial research
}

\section{Washington}

The great White House hope that scientific research can be harnessed to the cause of industrial innovation has evoked a quick response elsewhere in the United States government. Other agencies are understandably keen to share in the action. At the National Science Foundation, the most immediate result will be to precipitate the reorganisation over which the National Science Board has been agonizing for several months.

Reorganization will dominate the agenda for a public meeting between the acting director of the Foundation, Dr Donald N. Langenberg, some members of the National Science Board and the chairmen of the foundation's advisory committees which has been arranged for Saturday this week (13 September). The meeting will be open to members of the public, who will be able to chip in.

The National Science Board is hoping to have completed these and other consultations in time to make a final decision at its meeting in October. Failure to do so would mean that the proposed reorganization could not be built into the federal budget cycle, which might mean that some changes could not be carried out until October 1982.

The most obvious effect of the proposed reorganization will be to rename the Directorate of Engineering and Applied Science the Directorate of Engineering. More than nomenclature is involved, however - it is intended that each of the existing directorates of the NSF should be more directly concerned with the needs of applied science, while the new Engineering Directorate should vigorously support engineering research in universities.

Novel and explicit mechanisms for fostering industrial innovation are thus not a part of the proposed reorganization. Rather, the NSF is relying on the authority it already has to support industrial research. The scheme for funding joint industry-university projects is doing well. The NSF is also proud of the cooperative research centre in polymer science established at Massachusetts Institute of Technology (and now entirely supported by industrial companies). The analogous research centre for the furniture industry in North Carolina has been less successful.

These proposals are likely to win support. There will be more dispute about the proposal, part of the same package, to set up a Social Science Directorate even though the chief effect would be a repackaging of existing divisions (including the new programme in "decision and management" science). One objection is almost certain to be that "neural sciences", linked with “behavioural science", should not be separated from the rest of biology.
Under the new scheme, the foundation's existing rag-bag directorate (for Scientific, Technological and International Affairs) would take over responsibility for programmes such as those for supporting small business research and affirmative action of various kinds.

By Saturday's meeting, NSF will no doubt have been spurred on by Congressman George Brown's congressional subcommittee, to which Dr Lewis Branscombe (Chairman of the NationaL Science Board) and $\mathrm{Dr}$ Langenberg are due to give evidence. $\mathrm{Mr}$ Brown is using his bill to set up a National Technology Foundation (unlikely ever to become law) as a way of urging on everybody in sight the importance of research as a spur to industrial innovation and production.

Meanwhile, the Department of Commerce has stolen a march on sther potential competitors for the new funds that may become available in January by announcing its plans to set up three cooperative industrial research centres dealing with welding, lubrication and powdered metal processing. The Department of Commerce will spend $\$ 5.2$ million of its own money on the projects, for which proposals are being sought, and hopes that its own contributions to the cost of the centres will shrink to 20 per cent after five years.

\section{Appointments and elections ahead}

\section{Washington}

After several nail-biting weeks, it now seems that the US Senate will confirm the nomination of Dr John B. Slaughter as Director of the National Science Foundation some time during the week beginning 15 September. It is now thought that the differences, political and procedural, which have arisen over $\mathrm{Dr}$ Slaughter's nomination as NSF director (originally announced early in July), will be found to have melted away (or to have been buried) at a meeting of the Senate Committee on Labor and Human Resources due to be held tomorrow, 12 September.

The first stumbling block to $\mathrm{Dr}$ Slaughter's confirmation was ironically the reinvocation by Republicans in the Senate of a principle first mentioned by Democrats in the closing months of the first Nixon Administration in 1972 - the doctrine that fixed-term presidential appointments should not be confirmed as soon as this before a presidential election.

Formally, the directorship of the NSF is a six-year appointment, although the statutes allow the President to remove a director from office at any time. In practice, however, a president following such a course would have to contend with the scientific community's view that the directorship of the NSF is not a political appointment in the ordinary sense. Dr Slaughter, when his appointment is confirmed, will be especially hard to dislodge, for he would be the first black American to head an important agency.

Technically, Dr Slaughter's confirmation as NSF director awaits only the vote of the US Senate as a whole, having been recommended ("reported out") by Senater Edward Kennedy's subcommittee on Health and Scientific Research. In practice, the recommendation is flawed by the way in which Democratic members of the subcommittee carried it without a proper quorum. Nobody wants the issue to be debated by the Senate as a whole. The emollient now discovered is a full meeting of the Committee on Labor and Human Relations at which Dr Slaughter's nomination will be on the agenda but (it is hoped) not discussed. The White House has no doubt been reminded of the quip, usually an ethnic slur, "with friends like that, who needs enemies?",

Dr Slaughter's problems (and the NSF's) may melt away, but Dr Al Carnesale, the putative chairman of the Nuclear Regulatory Commission, is certain to have a rougher ride. Carnesale's nomination, the confirmation of which is in the gift of a subcommittee of the Senate Committee on Environment and Public Works, is frankly acknowledged to be political, and for a specific reason. Carnesale, now a tenured professor at the Kennedy Institute at Harvard University, is committed to the view that breeder reactors are economically irrelevant while the price of uranium is as low as at present. Mr Ronald Reagan, the Republican presidential candidate, disagrees. The chances are that in the circumstances Dr Carnesale will have to bide his time until after the election.

Speculation about other post-election changes is already rife, and the odds are shortening on the proposition that $\mathrm{Dr}$ Frank Press, now the President's Science Advisor and Director of the Office of Science and Technology Policy, will finish up next spring as president of the National Academy of Sciences. A spokesman of the NAS confirmed last week that Dr Press is a "leading candidate" to succeed Dr Philip Handler, whose second six-year term ends next June.

Procedurally, however, there is a long way to go before this appointment will be decided. Proposals by the nominating committee have to be approved by the Council of the Academy in October.

The by-laws of the academy require that the nominating committee should "assure itself that each proposed nominee will be 
willing and able to serve if elected", which presumably implies a detailed discussion of the terms on which a "proposed nominee" would take the job.

Thereafter the council of the academy will inform the members, who have until 1 December to make alternative nominations (which must be supported by at least fifty members' signatures). If necessary, ballot papers are distributed by 15 December and must be returned by 15 January 1981. In principle, the council can put more than one name to the membership, but it has not in recent years done so. The present procedure, devised only in the $1960 \mathrm{~s}$, appears in the 1980 s to be calculated to maximize the embarrassment of the "proposed nominee" and of the academy as a whole.

\section{Bell Research Labs Split possible?}

\section{Washington}

There is much consternation at the Bell Telephone Laboratories at the unexpected announcement last week that the parent company, American Telephone and Telegraph (AT\&T), is to split into two quite separate operating companies. This move, which has been prompted by a decision of the Federal Communications Commission (FCC) made public in May, may be followed at some later stage by a decision that Bell Labs itself should be split in two.

Scientists working at Bell Labs fear that such a development would impair the quality of the organization's research. For the time being, however, uncertainty rather than anxiety rules. No decision has been made as yet about the consequences of the split in the parent company for the research organization.

The crucial decision of the FCC (known as the Final Decision on the Second Computer Inquiry) is the latest stage in the FCC's decade-long attempt to adjust the rules for regulating the public telephone networks to meet new technical needs. Since 1968, the FCC has held that companies such as AT\&T should not enjoy the exclusive right to supply terminal equipment for their telephone lines and other channels of communication.

More recently, the difficulties of regulating the common carrier networks have increased with the development of data processing networks, domestic satellite communications and the prospect of other technical developments. For the past four years, the FCC has been searching for a definition that would allow the networks to supply some kinds of equipment but prohibit them from supplying other items.

In its latest ruling, the commission has abandoned this exercise in semantics and opted for a more radical solution. In future, it says, large common carriers of electronic signals must be concerned only with the development and management of the network. If they wish to supply terminal equipment as well, they must do so through a separately constituted company with a distinctive board of directors, separate premises and so on.

Although the same rule would apply in principle to all telephone companies in the United States, for the time being the FCC has ruled that it should apply only to AT\&T and to General Telephone and Electronics, which operates some 8 per cent of the American telephone network in locations scattered from Florida to California.

The response of AT\&T to this radical proposal has been equally surprising. Although the company argued strongly against separation in its evidence to the FCC, on the grounds that vertical integration is beneficial, it announced last week that it would go ahead with the formation of two separate companies to be responsible respectively for the operation of the telephone network and the supply of terminal equipment (telephones included).

It is not yet clear whether the separation of the two parts of AT\&T will be as complete as the FCC requires. Moreover, the move does not imply that AT\&T accepts the commission's ruling - indeed, AT\&T is one of thirty objectors who are threatening to carry their case to the courts if the decision is not modified.

The complication for Bell Labs is that the research organization is a jointly owned subsidiary of AT\&T and of Western Electric, itself the subsidiary of AT\&T responsible for manufacturing terminal and network equipment. The FCC ruling is vague on the implications of the proposed split in AT\&T for research and development, saying only that affiliated companies would be required in future to buy research and development services from other affiliated companies at a fair valuation.

One obvious development, that most feared at Bell Labs, is that AT\&T may in the end be required to divide both Western Electric and Bell Labs itself into parts separately responsible for communications networks and for terminal equipment. AT\&T is also alarmed at the prospect that even separation of activities on which it has now embarked will impede the free flow of ideas between operations and research and development.

If there were to be a split of Bell Labs, the chances are that the largest part would go to the network side. Of the 1980 budget of $\$ 1,255$ million, more than 45 per cent was exclusively concerned with network operations. The remainder may be considered relevant to both sides of the telecommunications business.

How soon the future of AT\&T and of Bell Labs will be decided is a matter for conjecture. The FCC has set a deadline for the complete separation of AT\&T by March 1982, but will now be required to comment on the objections to its ruling, most probably in October or soon afterwards. If the courts accept that the objectors to the ruling have a case, several further months may elapse before the regulations have the force of law, in which case the deadline would no doubt be put back. Excessive delay is likely, however, to breathe life into the bills now languishing in Congress that aim more directly to regulate the public communications networks.

\section{NPT review conference}

\section{No declaration}

The Second Review Conference of the Non-Proliferation Treaty ended on Sunday (two days later than originally planned) with a smack in the face for the three sponsoring nuclear powers, the Soviet Union, the United Kingdom and the United States. Although the nuclear powers had been expecting trouble at the conference, largely on the grounds that they had been less diligent than required by the treaty in the pursuit of strategic disarmament and the fostering of civil nuclear developments elsewhere in the world, they were apparently taken aback also to find themselves criticized on the grounds that either Israel (not a signatory of the treaty) or West Germany (which is) had been helping with the development of nuclear weapons in South Africa.

The most immediate cause of trouble was the failure of the conference to agree on a report of the past month's proceedings at Geneva. The drafting process came to a fruitless end in the early hours of Sunday morning, and the conference was concluded later in its day.

By all accounts, the review conference has been rought going ever since the opening speeches were made in public during the first ten days. The government of Mexico appears to have taken the lead in asking that the nuclear powers should agree to a package of demands on arms control, including a declaration that they would abide by Salt II while awaiting ratification of that treaty, impose on themselves a moratorium on nuclear testing and allow the negotiations on the Comprehensive Test-Ban Treaty (conducted up to now between the three nuclear power signatories of the treaty) to be carried on with the UN Committee on Disarmament. For the nuclear powers, the sticking-point last weekend was this demand that such a declaration should be included in the final report of the review conference.

The overriding question now is whether the failure to produce an agreed report will be followed by mass defections from the treaty. The closing speeches at Geneva, including that from the Iraqi chairman, were variations on the theme that nuclear proliferation remains a serious danger, and that the conference had served to draw attention to many of the beneficial aspects of the treaty.

The discovery by several of the 